\title{
Experimental study on laminated bamboo lumber column
}

\author{
Chenwei $\mathrm{WANG}^{1, \mathrm{a}}$, Huizhong ZHANG ${ }^{1, \mathrm{a}^{*}}$, Chenjie $\mathrm{ZHAO}^{1, \text { a }}$, Chenge ZHANG ${ }^{1, \text { a }}$, Tongwei CAO ${ }^{1, \text { a }}, \mathrm{Haoran} \mathrm{DONG}^{1, \text { a }}$, \\ Jieying DING ${ }^{1, a}$, Zhenhua XIONG ${ }^{2, b}$, Xiaohiong XIONG ${ }^{3, c}$, Wenfeng LIU ${ }^{4, d}$, Kangwen WU ${ }^{3, e}$, Rong Liu ${ }^{1, a}$, Wen Ding ${ }^{1, a}$, \\ and Ziwen YAN ${ }^{2, b}$ \\ ${ }^{1}$ College of Civil Engineering, Nanjing Forestry University, Nanjing 210037, China \\ ${ }^{2}$ Ganzhou Sentai Bamboo Company LTD, Ganzhou 341001, China \\ ${ }^{3}$ Jiangxi Precious Bamboo Company LTD, Ganzhou 341001, China \\ ${ }^{4}$ Jiangsu Fashion Safety Monitoring Consulting Co. LTD, Zhenjiang 212009, China
}

\begin{abstract}
This paper presents and discusses the experimental study on the mechanical properties of LBL column both under axial and eccentric compression. The results shows that the ultimate load for the eccentric compression specimens with the eccentricity values of $30 \mathrm{~mm}$ and $110 \mathrm{~mm}$ are $95.2 \mathrm{kN}$ and $31.8 \mathrm{kN}$ respectively. Eccentricity is one of the main influencing factors for the ultimate bearing capacity of the LBL columns. Because of the vulnerability of the mechanical connections or natural nodes to tensile stress and secondly, laminated bamboo is vulnerable to defects that has more detrimental influence on the tensile resistance of the material. The variation in strain for the laminated bamboo lumber column sections is linear throughout the loading process, following standard normal section bending theory which is similar as that for the beam.
\end{abstract}

\section{Introduction}

As a sustainable green building material, bamboo has attracted more and more researchers' attention [1-28]. Original bamboo culm has low rigidity and limited diameter. In order to solve these problems, industrial bamboo materials appeared in different forms such as parallel bamboo strand lumber (PBSL) [5-10], laminated bamboo lumber (LBL) [11-28] and so on. Laminated bamboo lumber (LBL) is made by laminating the thin flat bamboo strips together with adhesive under a certain treatment and the structural size could be controlled in the factory.

In order to apply laminated bamboo lumber to engineering area, many scientists [11-28] have done a lot of research on manufacturing technology and mechanical properties. Correal et al. [12] studied the adhesive bond performance in glue line shear and bending for glued laminated guadua bamboo. Verma et al. [13-14] have investigated the stiffness and strength of four layered laminate bamboo composite at macroscopic scale. Lee et al. [15] have studied the properties of laboratory-made laminated-bamboo lumber. Yeh et al. [16] has investigated finger joint performance of structural laminated bamboo member. Varela et al. [17] have investigated cyclic performance of glued laminated guadua bamboo-sheathed shear walls. Taheri et al. [18] have studied buckling response of glue-laminated columns reinforced with fiberreinforced plastic sheets. Li et al. [19-21] have studied the flexural performance of laminated bamboo lumber beam and the ultimate load calculation formula for the LBL beams were proposed. Axial compression performance of LBL has been studied by Li et al. [22-24] and Su et al. [25]. $\mathrm{Li}$ et al. [26-28] also investigated the eccentric compression performance of LBL columns. Even though some researchers have studied the mechanical properties of laminated bamboo lumber column, the study for it is limit. There is still no standard for LBL columns under compression. More work needs to be done to investigate the mechanical performance for LBL columns.

This paper mainly studies mechanical properties for LBL columns based on the former research. In order to know the compression behaviour of LBL columns, the study will examine in detail the behaviour of structural members constructed from laminated bamboo lumber with a design dimension of $76 \mathrm{~mm} \times 76 \mathrm{~mm} \times 800 \mathrm{~mm}$.

\section{Materials Information and Test}

Moso bamboo, harvested at the age of 3-4 years, was chosen for manufacturing laminated bamboo lumber columns. Phenol glue was used to manufacture the column specimens. Single layers were made first, and then they were pressed together to form the blocks (Figure 1). The pressing temperature was $140 \pm 5^{\circ} \mathrm{C}$ and the transverse compression was $1.82 \mathrm{MPa}$ for both the sheets and the blocks, and a confining pressure of $4.74 \mathrm{MPa}$ was used when manufacturing the sheets. Considering axial compression and eccentric compression with two

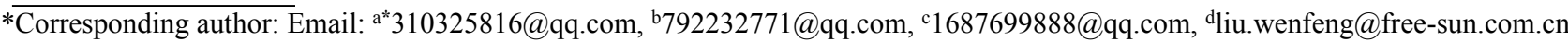

e767057291@qq.com, 
eccentricities of $30 \mathrm{~mm}, 110 \mathrm{~mm}, 5$ column specimens (three for axial compression) were constructed with the cross-section of $76 \mathrm{~mm} \times 76 \mathrm{~mm}$ and the length of $800 \mathrm{~mm}$. The eccentric direction is tangential eccentric direction.

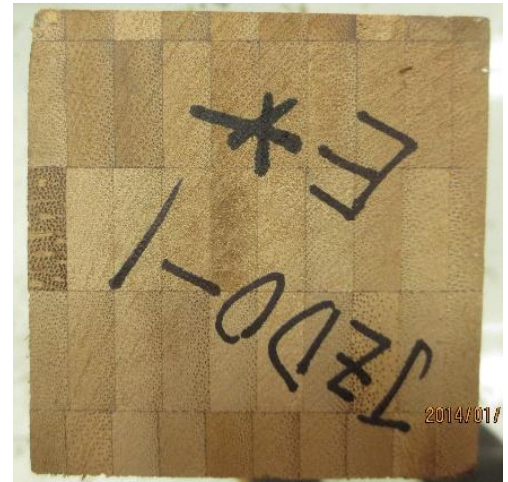

Figure 1 Laminated bamboo lumber (LBL)

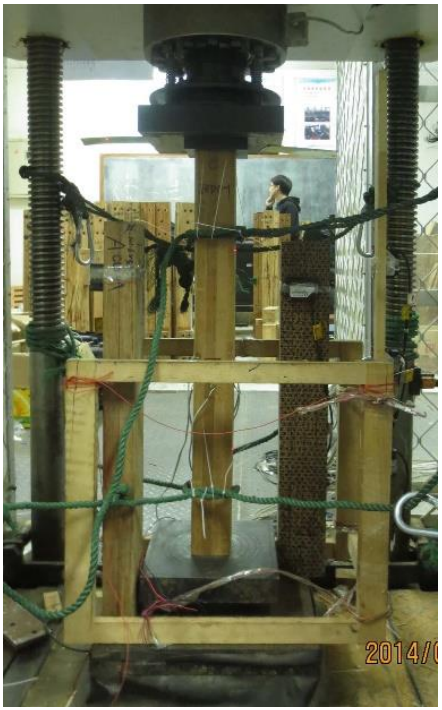

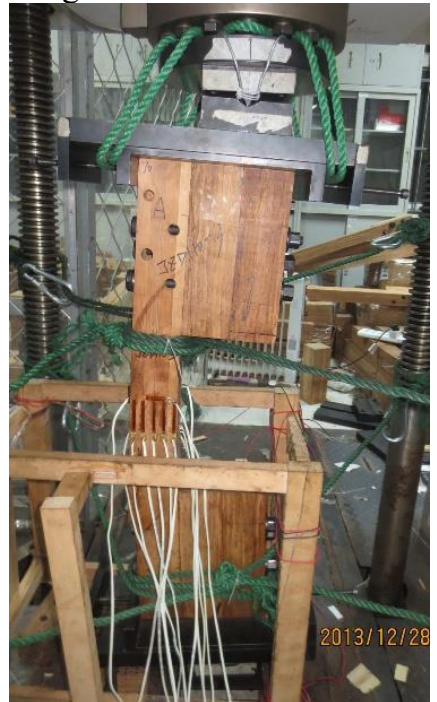

Axial compression test photo and eccentric compression test photo can be seen from Figure 2 and Figure 3 respectively. Both the axial and lateral displacements were measured by Laser Displacement Sensors for all columns. Two main strain gauges along lateral and longitudinal directions were placed at the midheight of specimens for axial compression tests. While for the columns under eccentric compression, besides two strain gauges were placed at the mid-height of four side surfaces, four more strain gauges were used on one side surface as can be seen from Figure 3. The loads were applied using a microcomputer-controlled electrohydraulic servo universal testing machine with a capacity of $1000 \mathrm{kN}$ with a TDS-530 Data Acquisition System.

The load was applied initially through load control in the elastic stage, and then was changed to displacement control before the proportional limit. The total loading time was controlled between 8-12 minutes. The test was continued at a certain displacement rate until the load reduced by $15 \%$ of the ultimate load and the specimen had sustained significant damage.

\section{Test results and analysis}

As for the columns under axial compression, the specimens behaved elastically at beginning and then buckling failure happened to them. The specimens bent to one direction suddenly. With the increasing of load and obvious deflection, cracks appeared. Finally the specimens crushed and the load values decreased. Typical final photos for the specimens under axial compression can be seen from Figure 4 and the ultimate load for three specimens are $274.7 \mathrm{kN}, 270.2 \mathrm{kN}, 275.0 \mathrm{kN}$ respectively.

As for the specimens under eccentric compression, similar to the specimens under axial compression, the column specimens behaved elastically at beginning then followed by some plastic deformation with increasing load. The stiffness decreased in the plastic-elastic stage. With the increasing of load and obvious deflection, cracks (accompanied by a slight noise) appeared on the tensile surface D. The load application was stopped when the load was reduced by $15 \%$ of the ultimate load and the specimen sustained significant damage. Except for the compression surface B, cracks were visible on other three side surfaces. It was obvious that failure was triggered due to bending for all the two column specimens under eccentric compression. Typical final failure photo can be seen from Figure 5. The ultimate load for the eccentric compression specimens with the eccentricity values of $30 \mathrm{~mm}$ and 110 $\mathrm{mm}$ are $95.2 \mathrm{kN}$ and $31.8 \mathrm{kN}$ respectively. Compared with the axial compression results, eccentricity is one of the main influencing factors for the ultimate bearing capacity of the LBL columns. The ultimate load for the specimens with the eccentricity values of $30 \mathrm{~mm}$ and $110 \mathrm{~mm}$ decreased by $65.2 \%$ and $88.4 \%$ respectively.

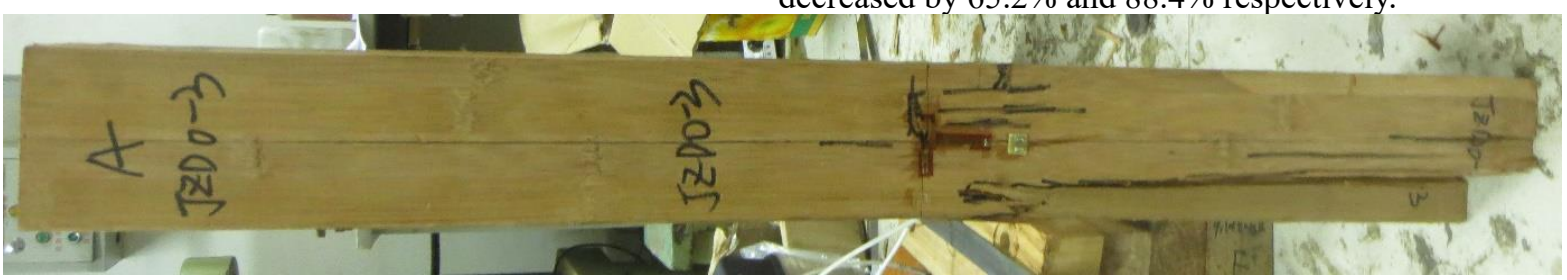

(a) Face A 


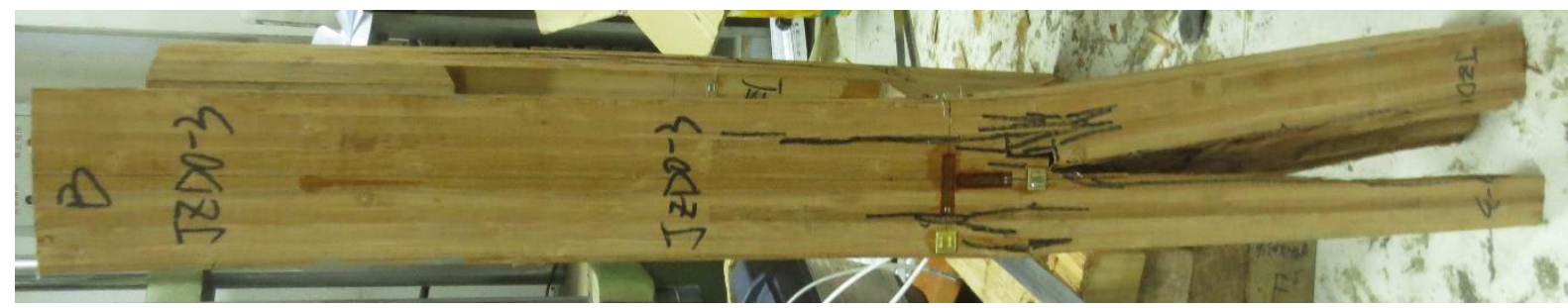

(b) Face B

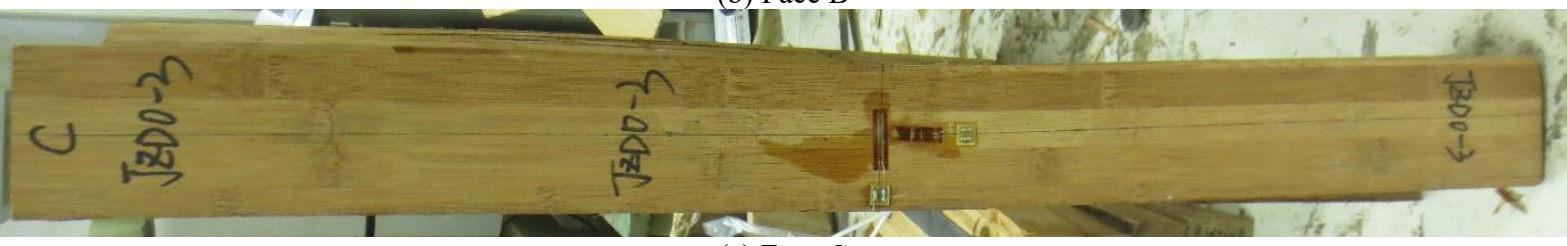

(c) Face $\mathrm{C}$

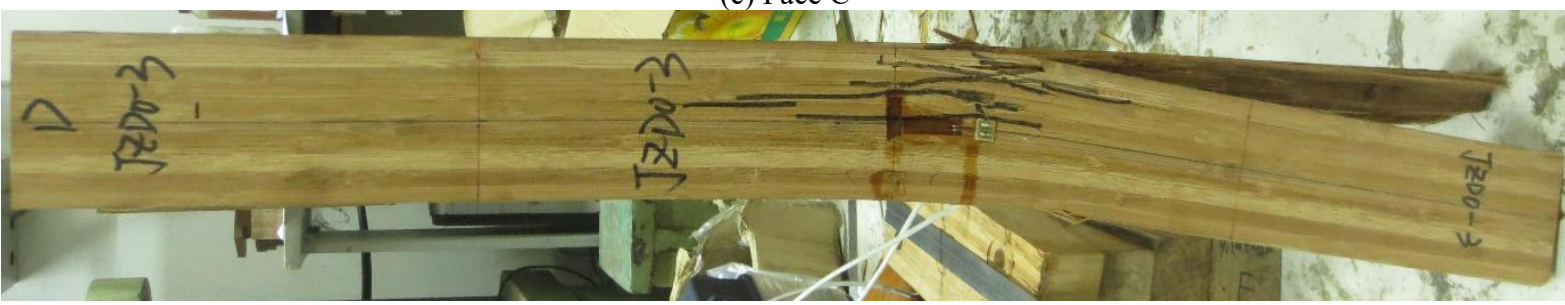

(d) Face D

Figure 4 Typical failure photos for axial compression specimen

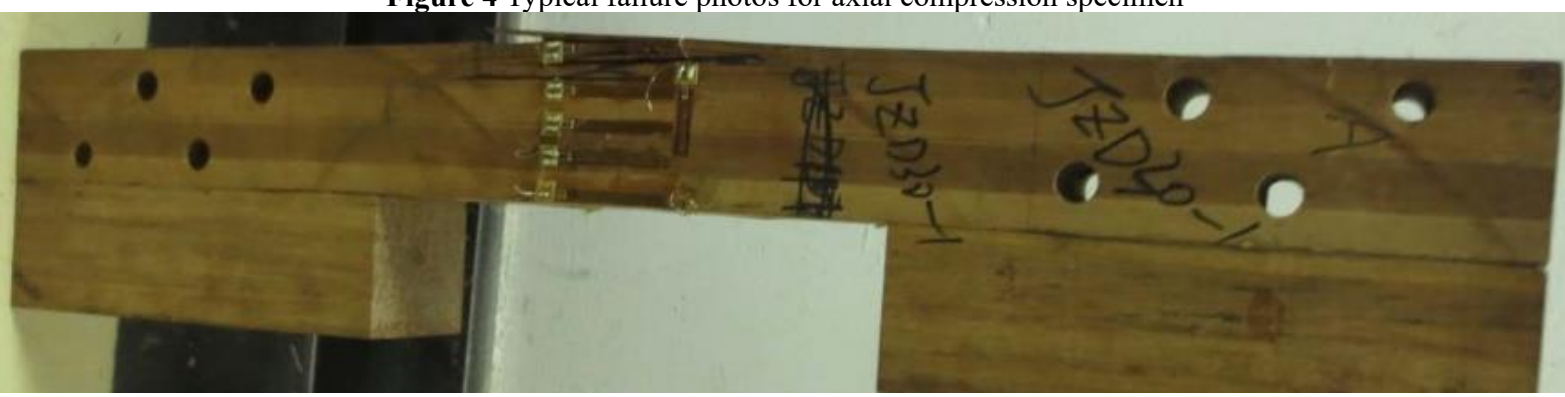

(a) Face A

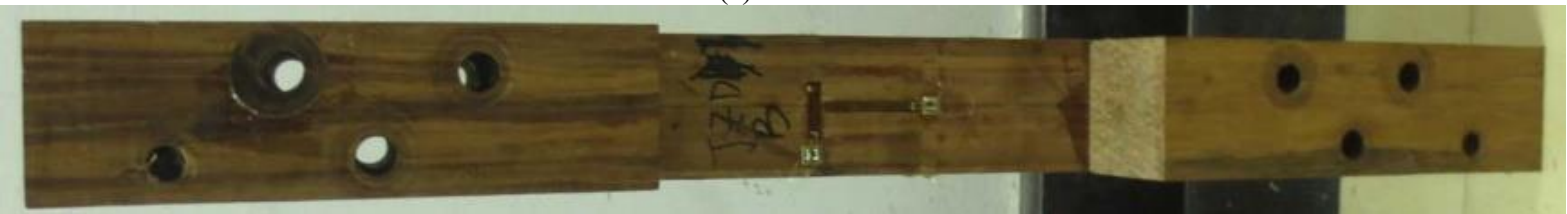

(b) Face B

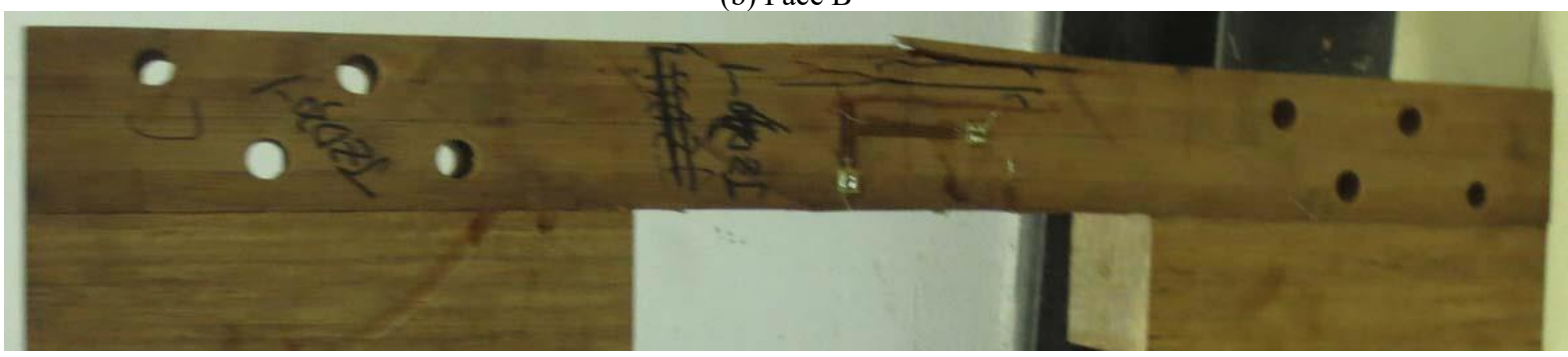

(c) Face $\mathrm{C}$

Figure 5 Typical failure photos for eccentric compression specimen

\section{Load vs strain relationship for LBL columns}

Figure 6 shows the variations in longitudinal strains at the mid-heights of four side surfaces. As can be seen from the figures, all strains clearly displayed an initial elastic phase. The longitudinal strain values for face $\mathrm{A}$ and $\mathrm{C}$ were always consistent during the whole loading process, and with increasing eccentricity observed strains on faces A and $\mathrm{C}$ became insignificant. The mechanical behaviour of the columns with higher eccentricities resembled those observed for beams. Face B being subjected to the highest compression, always showed maximum deformations both in longitudinal and transverse direction. Although, failure was always triggered on the tension surface: firstly, because of the vulnerability of the mechanical connections or natural nodes to tensile stress and secondly, laminated bamboo is vulnerable to defects that has more detrimental influence on the tensile resistance of the material. 


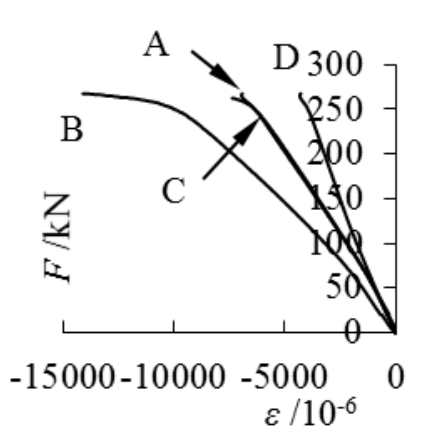

(a) JZD0-2

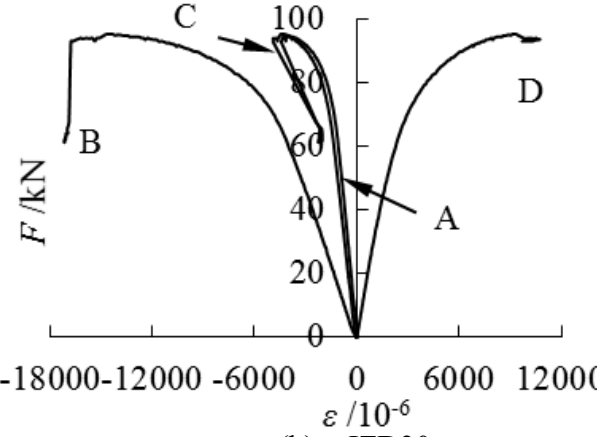

(b) JZD30

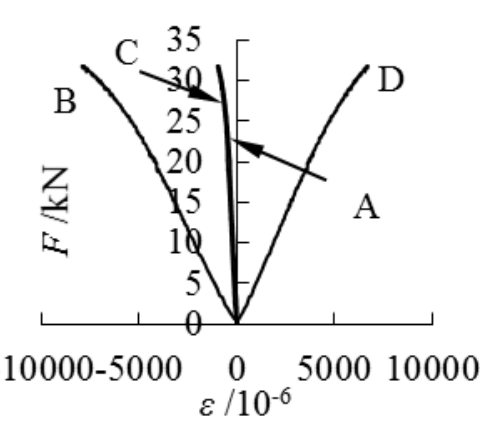

(c) JZD110

Figure 6 Load-longitudinal strain curves each group. The variation in strain for the laminated bamboo lumber column sections is linear throughout the loading process, following standard normal section bending theory which is similar as that for the beam ( $\mathrm{Li}$ et al [19-21]).

Fig. 7 shows the strain profile through the loading process for the mid-height cross-section of typical specimens for

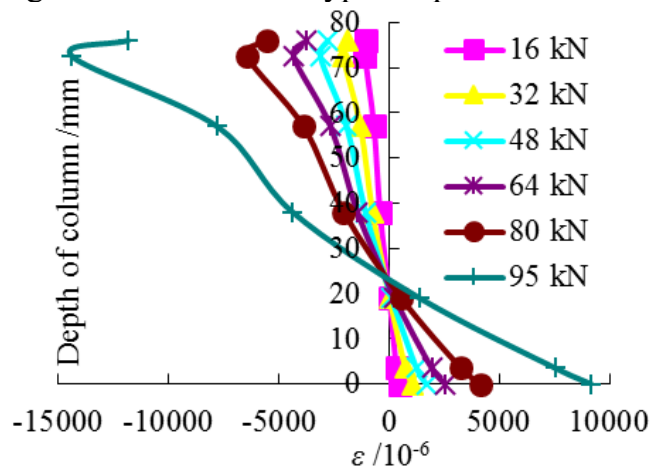

(a) JZD30

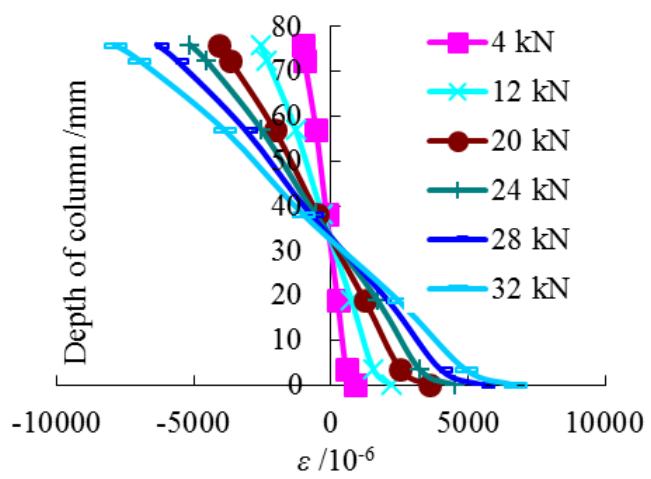

(b) JZD110

Figure 7 Typical strain profile development for the mid-span cross-section

\section{Conclusion}

This paper presents and discusses the experimental study on the mechanical properties of LBL column both under axial and eccentric compression. The results shows that the ultimate load for the eccentric compression specimens with the eccentricity values of $30 \mathrm{~mm}$ and $110 \mathrm{~mm}$ are $95.2 \mathrm{kN}$ and $31.8 \mathrm{kN}$ respectively. Eccentricity is one of the main influencing factors for the ultimate bearing capacity of the LBL columns. The ultimate load for the specimens with the eccentricity values of $30 \mathrm{~mm}$ and 110 $\mathrm{mm}$ decreased by $65.2 \%$ and $88.4 \%$ respectively. Because of the vulnerability of the mechanical connections or natural nodes to tensile stress and secondly, laminated bamboo is vulnerable to defects that has more detrimental influence on the tensile resistance of the material. The variation in strain for the laminated bamboo lumber column sections is linear throughout the loading process, following standard normal section bending theory which is similar as that for the beam.

\section{Acknowledgements}

This work was financially supported by the National University students practical and innovation training project (No. 201610298003Z, 201710298056Z), Postgraduate Research Innovation Project of Jiangsu Province (No. KYCX17_0831), the Project of Ministry of
Housing and Urban-Rural Development of the People's Republic of China (No. 2014K4023), Project of the Housing and Urban-Rural Development Bureau of Jiangsu Province (No. JS2012ZD34), practical and innovation training project of Nanjing Forestry University (2017NFUSPITP180, 2017NFUSPITP182, 2017NFUSPITP183), and a Project Funded by the Priority Academic Program Development of Jiangsu Higher Education Institutions.

\section{References}

1. Li Y, Xu B, Zhang Q, et al. Present situation and the countermeasure analysis of bamboo timber processing industry in China. Journal of Forestry Engineering, 2016, 1(1):2-7.

2. Huang $M$, Zhang $\mathrm{X}, \mathrm{Yu} \mathrm{W}$, et al. Mechanical properties and structure characterization of bamboo softened by high temperature steam. Journal of Forestry Engineering, 2016, 1(4):64-68.

3. Chen G, Zhou T, Li C, Zhang Q, Li H. Experimental study on the OSB webbed bamboo beams. Journal of Nanjing Forestry University (Natural Science Edition), 2016, 40(05): 121-125.

4. $\mathrm{Yu} \mathrm{Z}, \mathrm{Wu} \mathrm{Z}, \mathrm{Su} \mathrm{T}$. Microstructure analysis of the coating permeability of laminated bamboo panel for furniture $[\mathrm{J}]$. Journal of Forestry Engineering, 2016, 1(2):130-134. 
5. Zhang W, Jiang W, Tang R. Study on short-term bending creep behavior and microstructure of bamboo scrimber[J]. Journal of Forestry Engineering, 2017, 2(3):33-37.

6. Li H, Su J, Wei D, Zhang Q, Chen G. Comparison study on parallel bamboo strand lumber under axial compression for different directions based on the large scale[J]. Journal of Zhengzhou University (Engineering Science), 2016, 37(2): 67-72.

7. Su J, Fan Wu, Li H, P Yang. Experimental research on parallel bamboo strand lumber column under axial compression[J]. China Sciencepaper, 2015, 10(1): 3941.

8. Li H, Su J, AJ Deeks, Zhang Q, Wei D, Yuan C. Eccentric compression performance of parallel bamboo strand lumber column $[\mathrm{J}]$. BioResources, 2015, 10(4): 7065-7080

9. Li H, Wei D, Su J, Yuan C, Chen G. Experimental study on PSBL under eccentric compression [J]. Journal of Building Materials, 2016, 19(3): 561-565.

10. Zhang S, Li C, Xiao Z, et al. Bending strength and loading simulation analysis of bamboo scrimber Ishaped beam $[\mathrm{J}]$. Journal of Forestry Engineering, 2017, 2(1):125-129.

11. Li H, Zhang Q, Wu G, Xiong X, Li Y. Review on laminated bamboo lumber[J]. Journal of Forestry Engineering, 2016, 1(6): 110-116.

12. Correal J. F., Ramire L.F.. Adhesive bond performance in glue line shear and bending for glued laminated guadua bamboo[J]. Journal of Tropical Forest Science, 2010, 22(4): 433-439.

13. Verma C.S., Chariar V.M.. Stiffness and strength analysis of four layered laminate bamboo composite at macroscopic scale[J]. Composites part BEngineering, 2013, 45(1): 369-376.

14. Verma C.S., Chariar V.M.. Development of layered laminate bamboo composite and their mechanical properties[J]. Composites part B-Engineering, 2012, 43(3): 1063-1069.

15. Lee AWC, Bai XS, Bangi AP. Selected properties of laboratory-made laminated-bamboo lumber[J]. Holzforschung, 1998, 52(2): 207-210.

16. Yeh M, Lin Y. Finger joint performance of structural laminated bamboo member[J]. Journal of Wood Science, 2012, 58(2): 120-127.

17. Varela S., Correal J., Yamin L., Ramirez F.. Cyclic
Performance of Glued Laminated Guadua BambooSheathed Shear Walls[J]. Journal of Structural Engineering, 2013, 139(11): 2028-2037.

18. Taheri F., Nagaraj M., Khosravi P.. Buckling response of glue-laminated columns reinforced with fiberreinforced plastic sheets[J]. Composite Structures, 2000, 50: 207-216.

19. Li H, Su J, Zhang Q, Chen G. Experimental study on mechanical performance of side pressure laminated bamboo beam[J]. Journal of Building Structures, 2015, 36(3): 121-126.

20. Li H, Deeks AJ, Zhang Q, Wu G. Flexural performance of laminated bamboo lumber Beam[J]. BioResources, 2016, 11(1): 929-943

21. Li H, Wu G, Zhang Q, Deeks AJ, Su J. Ultimate bending capacity evaluation of laminated bamboo lumber beams [J]. Construction and Building Materials, 2018, 160: 365-375

22. Li H, Zhang Q, Huang D, Deeks AJ. Compressive performance of laminated bamboo[J]. Composites Part B: Engineering, 2013, 54(1):319-328

23. Li H, Zhang Q, Wu G. Stress-strain model under compression for side pressure laminated bamboo[J]. Journal of Southeast University (Natural Science), 2015, 45(6): 1130-1134.

24. Li H, Su J, Zhang Q, Deeks AJ, Hui D. Mechanical performance of laminated bamboo column under axial compression[J]. Composites Part B: Engineering, 2015, 79: 374-382.

25. Su J, Li H, Yang P, Zhang Q, Chen G. Mechanical Performance Study on laminated bamboo lumber column pier under axial compression[J]. China Forestry Science and Technology, 2015, 29(5): 89-93.

26. Li H, Wu G, Zhang Q, Su J. Mechanical evaluation for laminated bamboo lumber along two eccentric compression directions[J]. Journal of wood science, 2016, 62(6):503-517

27. Li H, Chen G, Zhang Q, Ashraf M, Xu B, Li Y. Mechanical properties of laminated bamboo lumber column under radial eccentric compression[J]. Construction and Building Materials, 2016, 121: 644652

28. Li H, Wu G, Zhang Q, Chen G. Experimental study on side pressure LBL under tangential eccentric compression[J]. Journal of Hunan University (Natural Science), 2016, 43(5): 90-96. 